\title{
Supervision of the Community Meeting
}

\section{Experience in an adolescent unit}

Tony JAFFA, Senior Registrar in Child and Adolescent Psychiatry, Hill End Hospital, St Albans, Hertfordshire

\begin{abstract}
The problem
There had been repeated staff dissatisfaction with the community meetings. Particular concerns included staff interrupting each other; frequent changes of theme; insufficient time for adolescents to speak or answer questions before the next staff intervention; some staff, particularly the more experienced, tending to fill the time with their questions or contributions. Repeated discussion of the meetings resulted in transient improvements lasting only until the next period of competition between eager therapists, or the next assertion of 'need to know' by the oncoming shift.
\end{abstract}

\section{The setting}

Hill End Adolescent Unit is the psychiatric in-patient unit for boys and girls under 16 years of age in the North West Thames Regional Health Authority. ${ }^{1}$ An integral part of the functioning of the unit is the daily community meeting. ${ }^{2}$ The prime purpose of this is handover of information. A secondary purpose, though one obviously important to a staff of helping professionals, is the practice of therapy.

The meeting is run by an adolescent. After reports on the adolescent group and the staff, the time is divided equally to allow 'handing over' of individual adolescents. Any time left over gives an opportunity for staff and other adolescents, unfortunately usually the former, to ask questions or add to what has been said.

\section{The suggestion}

In February 1986 a new batch of student nurses began their placement at Hill End Adolescent Unit. One of these found the community meetings intolerable and suggested a possible change. He had observed family therapy sessions involving live supervision ${ }^{3}$ and wondered whether this model could be used to improve the community meetings. Initially his suggestion fell on almost deaf ears but when repeated a few times it was considered more seriously.

Could the role of supervisor as used in family therapy be transposed to the setting of the community meeting? How would the relationship between the supervisor and the rest of the staff be affected by the much larger numbers of staff than are found in family therapy? Would the supervisor's function include consideration of process as in family therapy or would it be largely concerned with behaviour in isolated pieces?

\section{A start}

After much negotiation and a relatively poor community meeting it was decided in the unit administration meeting ${ }^{4}$ to try live supervision. Adolescents and staff were given one week's notice of the change and in this time staff practised supervising and being supervised in training sessions.

In the community meeting one member of staff sat in a chair outside the main circle and a colleague announced that this person was to supervise the staff group. The supervisor, most often a senior staff member, sat quietly throughout and reported back his or her experiences in a staff meeting held directly afterwards. From the start the supervision was associated with observed changes in staff behaviour. Adolescents were given more time to speak. There were fewer changes of theme and fewer interruptions from staff eager to have their say. More staff contributed, including those with less experience. Interestingly, these changes dated from the first supervised meeting itself and not in response to comments of the supervisors. In contrast to the earlier experience when staff discussion led to transient changes, the improvement persisted.

\section{Development}

Encouraged by this initial success, staff decided to continue and modify their use of the model. The role of supervisor was taken by more of the junior staff, including nursing and social work students. Supervisors became more detailed in their comments, mentioning behaviour of which they had approved or disapproved. Examples of the latter have included sitting in rows with stern expressions and folded arms, looking as though they were asleep, and speaking in inappropriately harsh tones.

\section{Staff discussion}

While the supervisor's contribution was generally welcomed, in some cases it was experienced as punitive and as reducing staff creativity. There was debate between those who regretted the inevitable inhibition of spontaneity, and those who pointed out that the inhibition of unhelpful spontaneous behaviour was one of the purposes of the supervision.

Some staff, particularly those who had had little previous experience of live supervision, wished to stop the experiment. Others said it had achieved its purpose and should be stopped for a time to see what happened. The majority, including most of the students, argued that awareness of the supervisor helped them to modify their behaviour: on one occasion a senior member of staff, who had been sitting with his eyes closed, was seen suddenly to open them and glance at the supervisor to see if he had been spotted. Although there was not unanimous agreement it was decided to continue with the supervision. 
Further development

Supervisors became more skilled in the way they reported back and were less often felt to be as punitive or oppressive. Some of the more senior supervisors began to intervene directly, for instance to point out where an adolescent had not been given an opportunity to answer a question. This more direct and immediate intervention was recognised as more in keeping with the 'true' practice of live supervision as seen in family therapy.

Although the supervision had been concerned mainly with items of behaviour, there began to be increasing emphasis on process. On one occasion the supervisor was able to point out how staff, holding firmly the hands and arms of an adolescent, had contributed to escalating disruption rather than diminishing it.

After three months, the initial improvement has been maintained and our impression is that the role of supervisor can be transposed from family therapy to the community meeting.

\section{Further extensions}

Some of the nursing staff who had previously run therapeutic groups as co-therapists, have differentiated their roles into therapist and live supervisor. The unit staff run seminars for helping professionals on a range of topics and live supervision has been used by some of the seminar leaders.

\section{Comment}

The staff of Hill End Adolescent Unit are finding ways to extend use of live supervision and believe that this model might be applicable in other settings and organisations.

\section{ACKNOWLEDGEMENT}

I would like to thank Matt Ellis who suggested live supervision of the community meeting.

\section{REFERENCES}

${ }^{1}$ Bruggen, P., Byng-Hall, J. \& Pitt-Aikens, T. (1973) The reason for admission as a focus of work for an adolescent unit. British Journal of Psychiatry, 122, 319-329.

2 _- DunNe, C. \& O'Brian, C. (1981) Daily meetings chaired by an adolescent in a psychiatric ward. Bulletin of the Royal College of Psychiatrists, 5, 20-22.

${ }^{3}$ SMITH, D. \& Kingston, P. (1980) Live supervision without a one-way screen. Journal of Family Therapy, 2, 379-387.

'Bruggen, P., Brilliant, B. \& IDE, S. (1982) Secrets and gossip: staff communication. Bulletin of the Royal College of Psychiatrists, 6, 117-119.

\section{Review}

Dementia in Later Life: Research and Action. Report of a WHO Scientific Group. London: HM Stationery Office. 1986. Pp 76. SwFr 10.00

This 74 page booklet, published by the World Health Organization as one of its technical reports, is based upon the deliberations of a scientific group which met for seven days to consider the various aspects of dementia in old age, and to point the way towards solving some of the problems. For problems apparently surround the classification of dementia, nor do cross national agreements over how the dementia syndrome might be reliably identified or its severity graded, exist. There is, however, agreement that dementia presents a major health hazard, even it appears, in third world nations.

Epidemiological research has been patchy, and concentrated largely in Northern Europe, North America and also in Japan where, unusually, dementia due to cerebral infarction predominates. Most progress has been made in identifying the neuropathological and neurochemical bases for Alzheimer's disease, now recognised as the commonest cause of dementia in most countries. The chapter on causes presents a comprehensive and coherent account of these aspects, supported by a large number of carefully selected references.
Other chapters are devoted to prevention and treatment; to coping with dementia; to the need for international collaborative research and to overall strategic issues. The authors of the report urge the establishment of core criteria for diagnosis; epidemiological studies aimed at early case detection; continuing multidisciplinary and collaborative biological researches into causality; systematic evaluation of present and proposed therapeutic approaches; study of the coping strategies adopted by families which contain a demented patient and, perhaps predictably, resource allocations which more truly reflect the size and importance of this problem, and the potentially horrendous financial and social cost of doing nothing.

I enjoyed reading this booklet, which I found very informative and worth its modest cost (SwFr 10.00, about f4.00) for the chapter on causes and the references alone. There is little that deserves criticism, except perhaps that it should have been published earlier, and one wonders why nearly three years elapsed between the meeting and the date of publication.

Newcastle General Hospital

G. BLESSED 